\title{
Uma análise institucionalista do papel do planejamento estratégico na Embrapa
}

\author{
Karine Daiane Zingler ${ }^{1}$ \\ Petula Ponciano do Nascimento ${ }^{2}$ \\ Leonardo Xavier da Silva ${ }^{3}$ \\ Glauco Schultz ${ }^{4}$
}

\begin{abstract}
Resumo
A Embrapa foi criada em 1973 para aumentar a produtividade da agricultura brasileira, em meio ao esgotamento do Processo de Substituição de Importações. Mas, ao longo do tempo o contexto institucional modificou-se, exigindo diferentes prioridades de pesquisa. Este artigo tem a intenção de analisar a evolução da estrutura de planejamento da Embrapa, seus objetivos e foco de pesquisa. O que foi realizado a partir da leitura de documentos e avaliação dos Planos Diretores, fontes bibliográficas sobre o assunto e sobre Economia Institucional. Verificou-se que a estrutura de planejamento de pesquisa passou de uma visão centrada na reprodução dos objetivos do governo federal na década de 1970 para uma integração maior com a sociedade na década de 1980 e inserindo o planejamento estratégico a partir da década de 1990. Com monitoramento das demandas da sociedade por tais técnicas, passouse também a diversificar a agenda de pesquisa, porém esta mudança é dependente em sua trajetória.
\end{abstract}

Palavras-chave: Embrapa, Instituições, Pesquisa Agropecuária; Inovação.

\section{An institutionalist analysis of the role of strategic planning at Embrapa}

\begin{abstract}
Embrapa was created in 1973 to increase the productivity of Brazilian agriculture, amid the exhaustion of the Import Replacement Process. But, over time, the institutional context has changed, requiring different research priorities. This article aims to analyze the evolution of Embrapa's planning structure, its objectives and research focus. What was done from reading documents and evaluating the Master Plans, bibliographic sources on the subject and on Institutional Economics. It was found that the research planning structure went from a vision centered on reproducing the objectives of the federal government in the 1970 s to a greater integration with society in the $1980 \mathrm{~s}$ and inserting strategic planning from the 1990s. Monitoring the demands of society for such techniques, it has also started to diversify the research agenda, however this change is dependent on its trajectory.
\end{abstract}

Key words: Embrapa, Institutions, Agricultural Research; Innovation.

1 Doutorado em Desenvolvimento Rural (PDGDR-UFRGS). Professora nos Cursos de Administração Pública e Agronomia da Universidade Estadual do Rio Grande do Sul (UERGS). https://orcid.org/0000-0002-4603-9037 E-mail:karine.zingler@gmail.com

2 Doutorado em Políticas Públicas, Estratégia e Desenvolvimento (PPED/IE/UFRJ). Pesquisadora da Empresa Brasileira de Pesquisa Agropecuária - Embrapa Solos (Rio de Janeiro, RJ). E-mail:petulapn@gmail.com

${ }^{3}$ Doutorado em Economia (UFRGS). Professor do Programa de Pós-Graduação em Desenvolvimento Rural (PGDR) e do Programa de Pós-Graduação em Agronegócios (PPGA) da Universidade Federal do Rio Grande do Sul (UFRGS).

E-mail: leonardo.xavier@ufrgs.br

${ }^{4}$ Doutorado em Agronegócios (UFRGS). Professor do Programa de Pós-Graduação em Desenvolvimento Rural (PGDR) e do Programa de Pós-Graduação em Agronegócios (PPGA) da Universidade Federal do Rio Grande do Sul (UFRGS).

E-mail: glauco.schultz@ufrgs.br 


\section{Introdução}

A agricultura brasileira tem passado por importantes transformações nas últimas cinco décadas, fruto das políticas agrícolas de modernização que passaram a ser utilizadas amplamente a partir dos anos 1960. E nisso, a Embrapa, que é uma organização pública de pesquisa, tem um papel fundamental à medida que foi criada para desenvolver tecnologias que alavancassem a produtividade agrícola do Brasil.

Conforme Duarte (2018), em entrevista concedida, Eliseu Alves declara que a Embrapa que foi oficialmente criada em 1973, surgiu para fornecer conhecimentos sobre a agricultura brasileira e a partir disso criar tecnologias próprias, de modo a promover o aumento de produção e produtividade dos estabelecimentos agropecuários que eram considerados atrasados. Era uma época em que o Brasil vivia o esgotamento do processo de substituições de importações, e a agricultura era vista como um dos entraves pela sua baixa produtividade, conforme destacam Gonçalves Netto (1997) e Fonseca (2003).

Então em sua fase inicial de atuação a Embrapa esteve muito preocupada em trazer resultados de pesquisa voltados ao aumento da produtividade, em um cenário em que políticas governamentais também enfocavam tais necessidades, como o II PND, amparada pelos governos militares. Porém, à medida que o contexto institucional se modificou, novos desafios foram impostos e novas respostas e resultados de pesquisa exigidos. A partir disso, a organização passou a estruturar-se na implementação do planejamento estratégico, com isso avaliando melhor as demandas da sociedade e governos e as internalizando em novos objetivos de pesquisa que passaram a contemplar outras prioridades para além dos aspectos quantitativos da produtividade.

A partir dessa análise inicial, pretende-se neste artigo analisar como evoluiu a estrutura de planejamento da Embrapa, bem como os objetivos organizacionais. O foco de pesquisa se dá a partir da leitura de documentos institucionais, como os Planos Diretores formulados, e também outros artigos publicados sobre o assunto. A pesquisa é bibliográfica e documental, em uma análise qualitativa e baseia-se em referencial teórico ligado à Economia Institucional nas contribuições especialmente de Douglass North. 


\section{Arcabouço teórico: Teoria Institucional e Planejamento Estratégico}

No campo teórico das Ciências Sociais Aplicadas uma das abordagens que tem se mostrado promissora para análise de processos evolutivos em perspectiva multidisciplinar é o institucionalismo. Especialmente na Economia, destaca-se a Nova Economia Institucional que passou a receber maior reconhecimento a partir de prêmios Nobel concedidos aos seus entusiastas desde a década de $1990^{1}$.

A análise teórica da Economia Institucional mostra que existem várias vertentes, mas que apesar de diferenças, apresentam importantes similaridades. Samuels (1995) indica os atributos fundamentais e que trazem convergência às análises institucionalistas: a) ênfase na evolução social e rejeição no ajuste automático neoclássico; b) mercados guiados pelas instituições, rejeição ao sistema autorregulador neoclássico; c) importância da tecnologia e sua promoção de mudanças sociais, econômicas e políticas; d) instituições são mecanismos de alocação de recursos e não necessariamente o mercado; e) valor está relacionado a instituições e não necessariamente a preços relativos; f) importância da cultura e sua interdependência com o ajuste institucional; g) economia não determinística e nem mecanicista; h) caráter multidisciplinar da Economia e do estudo das instituições.

Para tanto, a análise institucionalista que se pretende trazer nesta discussão é basicamente evolutiva, à medida que serve de base para interpretação das mudanças de agenda de uma determinada organização, a Embrapa, a partir da sua estrutura e ações de planejamento. Assim, a análise histórica apresenta um papel fundamental nos métodos institucionalistas, sendo que North $(1991,1994,2005,2018)$ destaca que ao longo do tempo as diferentes escolhas dos agentes levaram a distintas relações econômicas, sociais e políticas nos países, que resultaram em múltiplos graus de desenvolvimento ao redor do mundo.

Ao mesmo tempo, se percebe que as organizações têm certa dificuldade de romper com premissas ou objetivos iniciais para as quais foram criadas. Nesse sentido, há a centralidade do conceito de path dependence, ou dependência de trajetória, a partir da qual "Não podemos compreender as escolhas do presente (nem defini-las na modelação do desempenho) sem traçar a evolução incremental das instituições." (NORTH, 2018, p. 171-172) Ou seja, as escolhas do presente e do futuro são fortemente influenciadas por decisões e comportamentos do passado.

\footnotetext{
${ }^{1}$ Alguns Institucionalistas premiados: Ronald Coase (1991), Douglass North (1993), Oliver Williamson e Elinor Ostrom (2009)
} 
Dessa forma, mudanças nos objetivos e atuação tendem a levar em consideração as demandas do ambiente, mas também serem influenciadas pela cultura organizacional e escolhas do passado dentro da organização. Dessa forma a mudança tende a ser incremental, sendo rejeitadas rupturas radicais.

Em uma visão evolutiva que apresenta congruências com as contribuições de Douglass North, Veblen (1987) afirma que as instituições estão circunstanciadas por um ambiente externo que acaba por selecioná-las, em um processo que não está relacionado com eficiência, mas sim com aptidão ao ambiente. Além disso, Veblen (1898) reforça que os hábitos de pensamento do indivíduo em geral estão de acordo com as concepções da comunidade em que se vive, o ambiente social exerce influência no pensamento e comportamento dos indivíduos. Sobre a formação e evolução das instituições, Veblen (1987) destaca que o passado tem grande importância nesse processo, as instituições são passadas de geração em geração, mas apenas aquelas que conseguem se adaptar ao ambiente sobrevivem, as instituições evoluem para sobreviver.

North (2018) conceitua as instituições como: “[...] as regras do jogo em uma sociedade ou, em definição mais formal, as restrições concebidas pelo homem que moldam a interação humana. Por consequência, estruturam incentivos no intercâmbio humano, sejam eles políticos, sociais ou econômicos." (NORTH, 2018, p. 13) Tais restrições podem ser formais e informais. Por outro lado, as organizações são vistas como as jogadoras deste jogo.

North (2018) sistematiza as consequências das instituições para a análise econômica: a) as decisões políticas e econômicas são moldadas pelo contexto institucional, que muda no tempo e no espaço; b) as instituições existem e com isso economistas devem questionar os modelos comportamentais utilizados até então; c) noções e ideologias moldam a maneira como os indivíduos interpretam o mundo e fazem escolhas e as instituições desempenham um papel importante ao determinar o quanto elas são relevantes, isso afeta preços e as percepções dos atores; d) usar mais de interpretações de economia política e dos condicionantes institucionais nas análises macroeconômicas.

Então, nessa análise o ambiente é formado pelas instituições que determinam um sistema e ditam um contexto institucional que determina ou influencia fortemente as escolhas dos indivíduos. A partir dessa constatação e do fato de que o Estado tem importante papel direcionador da mudança ou da estabilidade, esse ferramental e aporte teórico parece 
consistente para analisar o comportamento de organizações de pesquisa estatais e seu papel na mudança institucional.

Para North (1994), a mudança ocorre porque as organizações e os atores querem fazer as coisas melhores, ou de maneira mais eficiente e, a partir disso, reestruturam suas trocas. Assim, a fonte fundamental para a mudança é a aprendizagem e esta é incentivada basicamente pela concorrência. "A velocidade da mudança econômica é uma função da taxa de aprendizagem, mas a direção dessa mudança é uma função dos retornos esperados para adquirir diferentes tipos de conhecimento." (NORTH, 1994, p. 362)

Mantzavinos, North e Shariq (2004, p.75) produzem uma análise da mudança institucional, baseada no processo de aprendizagem, pois, "A habilidade para aprender é a principal razão para a plasticidade do comportamento humano, e a interação das aprendizagens individuais dá origem à mudança na sociedade, política, economia e organizações".

Para North (2018) o foco da análise está nas instituições e o papel das organizações está mais voltado para a análise destas como "agentes de mudança institucional". "Assim, a ênfase está na interação entre instituições e organizações." (NORTH, 2018, p. 16-17). Pois, na visão do autor, organizações são criadas com determinados fins econômicos-institucionais, e no processo de tentativa de alcance desses objetivos, acabam sendo agentes de mudança institucional.

North (2018), destaca que as organizações em interação no ambiente institucional criam a estrutura de incentivos e oportunidades para a mudança institucional. É importante destacar o lock-in, ou tranca, a partir do qual as organizações têm incentivos para mudar o ambiente, mas ao mesmo tempo esse ambiente tenta restringir sua ação.

Quando se aplica essa análise às organizações se percebe que existe consistência muito grande dos pressupostos do planejamento estratégico com a indução da mudança organizacional que reflete em mudanças no ambiente institucional. Uma vez que as organizações utilizam ferramentas de administração estratégica e planejamento de modo a fazer a leitura do ambiente no qual estão inseridas, traçam seus objetivos e metas para manterem-se fortes nos mercados nos quais estão inseridas. Ou seja o ambiente interfere na condução de suas ações ao influenciar nos objetivos definidos, criando uma espécie de lock-in.

Conforme Mintzberg, Ahlstrand; Lampel (2000), a chamada Escola do Planejamento ganha espaço no âmbito dos estudos da Administração a partir da década de 1970 e logo se insere como prática nas organizações, como um procedimento formal embasado em números, e daí decorre a criação da chamada "Administração Estratégica". Em que uma das fases mais 
importantes do processo de planejar envolve, segundo Mintzberg, Ahlstrand; Lampel (2000), a análise do ambiente externo no qual a organização está inserida.

Já que conforme Chiavenato (2003) o planejamento decorre ou está assentado em algumas premissas que são a finalidade da organização juntamente com seus valores, princípios e avaliação das oportunidades e ameaças externas, bem como dos seus pontos fortes e fracos. Segundo o autor, é a partir destes que se formula o planejamento estratégico da organização, operacionalizado a partir da definição da sua missão, seus objetivos de longo prazo e políticas básicas. Estes servem de base para a formulação do planejamento tático que está relacionado aos programas de médio prazo, aos subjetivos e subpolíticas, que servem de fundamento para a formulação do planejamento operacional, relacionado aos programas de curto prazo, às metas e procedimentos. Basicamente existem três etapas do planejamento, o estratégico que é de longo prazo, o tático de médio prazo, e o operacional que está relacionado às metas de curto prazo. (CHIAVENATO, 2003)

Por sua vez, a administração estratégica, base do planejamento estratégico é conceituada pelo autor como "[...] a maneira pela qual uma organização pretende aplicar uma determinada estratégia para alcançar os objetivos propostos." (CHIAVENATO, 2003, p. 236) O autor ainda destaca os estágios do planejamento estratégico que são: formular os objetivos da organização, análise do ambiente externo, análise do ambiente interno da empresa, formular as alternativas de estratégias e escolher qual a estratégia a ser utilizada e desenvolver os planos táticos e operacionais a partir da estratégia escolhida.

Percebe-se, portanto, que o estudo do planejamento pode ser entendido a partir do uso da lente de análise da Economia Institucional, uma vez que a organização estabelece objetivos e metas de atuação a partir da observação do ambiente externo no qual está inserido. E este nada mais é do que o próprio ambiente institucional, sobre o qual Douglass North e Thorstein Veblen debruçam sua análise. É por meio do planejamento que as organizações observam as pressões e tendências advindas do ambiente e as internalizam por meio de estratégias e definição de objetivos e metas, e dessa forma desenvolvem a mudança institucional.

A partir disso, se analisa na próxima seção como evoluiu a estrutura de planejamento da Embrapa e como as alterações no ambiente passaram a ser incorporadas nos objetivos organizacionais. 


\section{0 planejamento na Embrapa}

Conforme Cabral (2005), o Planejamento está inserido desde o início das atividades da Embrapa, especificamente 1974 quando foi implantado o Sistema de Planejamento da Embrapa, via o Programa Nacional de Pesquisa Agropecuária (Pronapa). Sobre a orientação de pesquisa em termos técnicos destacou-se a implementação da abordagem em sistemas, para isso, foi necessário capacitar os pesquisadores para atuação dentro dessas normas e orientações.

A Deliberação 68/1974, da Empresa Brasileira de Pesquisa Agropecuária, Embrapa (1974), especificava ainda os instrumentos de planejamento a serem utilizados, o principal era o Plano Indicativo para a Pesquisa Agropecuária, que recomendava as prioridades de pesquisa da Embrapa e sua programação, elaborado a partir da análise dos planos do governo federal "Plano Nacional de Desenvolvimento" (PND) ou "Plano Básico de Desenvolvimento Científico e Tecnológico" (PBDCT) e orientações do Ministério da Agricultura.

Nesse período inicial, o planejamento organizacional era desdobramento dos objetivos do governo federal. Cabral (2005) explica que o Presidente Ernesto Geisel se mostrou muito interessado nas questões ligadas à Embrapa, tanto que logo no início do seu mandato reuniu-se com a diretoria e com o Ministro da Agricultura Alysson Paulinelli. Cabral (2005, p. 109) destaca as palavras do Presidente "[...] não admitia a importação de feijão, arroz, trigo, milho e leite. Para ele, a Embrapa só tinha sentido existir se, via pesquisa e a ajuda direta de crédito e assistência técnica, resolvesse o atendimento à demanda de alimentos essenciais à população brasileira." Ele cobrava, então, o comprometimento da diretoria cumprindo metas sobre suficiência na disponibilidade interna de alimentos e a partir disso daria apoio à organização, por meio da ampliação e também ajuda em captações externas, especialmente em bancos de desenvolvimento e Banco Mundial.

Conforme Castro (1984) a criação da Embrapa representou uma inovação, já que até então a política de modernização estava centrada na simples difusão de insumos modernos e máquinas, articulados em planos nacionais. Mas, com a Embrapa articulou-se uma mudança de enfoque com a integração com universidades e outras organizações públicas e privadas de pesquisa agropecuária, em uma preocupação estratégica com a agricultura brasileira.

Conforme Penteado et al. (2014), logo no começo da segunda gestão da Embrapa, em 1979, iniciou-se um processo de revisão do Sistema de Planejamento de Pesquisa, em função das alterações pelas quais passou a agricultura brasileira, bem como mudanças econômicas e 
políticas em curso. A partir disso foi criado o chamado Modelo Circular de Pesquisa, que apesar de ainda vincular-se à visão de curto prazo, passou a adotar uma orientação mais voltada ao produtor rural, com a uniformização da linguagem do planejamento no sistema cooperativo de pesquisa agropecuária, coordenado pela Embrapa. Também, a partir daí que se passou a inserir a percepção da importância de visualizar o ambiente externo, para além de simplesmente avaliar os planos de governo, incluindo então de forma muito superficial a noção estratégica. Porém, em uma visão unicamente vinculada ao produtor rural como demandante, sem analisar os demais elos da cadeia produtiva. (PENTEADO et al., 2014)

Ou seja, o contexto institucional se modificou a partir da distensão política do país e abertura com o enfraquecimento do modelo levado adiante pelos militares desde 1964. Com isso, a Embrapa que foi criada no governo militar percebia que também o ambiente econômico vinha se modificando e que seria importante "trazer" a sociedade para discutir as prioridades de pesquisa, não mais apoiada apenas nas demandas de governo.

O novo modelo de planejamento da pesquisa agropecuária criado em 1980 abrangia duas definições. A primeira foi o Programa Nacional de Pesquisa (PNP), relacionado a produto, recurso ou algum grande problema diagnosticado na agricultura, o qual era definido em reuniões com participação de pesquisadores, técnicos de atividades de desenvolvimento regional, organizações de crédito, cooperativas, organizações da extensão rural e produtores. A partir daí eram definidas as prioridades de pesquisa e os objetivos de curto, médio e longo prazo para aquele determinado produto, recurso ou "grande problema". E, assim, os PNPs se tornavam documentos orientadores que eram revisados e atualizados periodicamente, com coordenação em alguma unidade da Embrapa ou outra organização participante do sistema de pesquisa agropecuária. A outra definição era a de projeto de pesquisa, que deveria estar vinculado a algum problema relevante em conformidade com algum PNP, com especificação do problema e da estratégia adotada para solucioná-lo. (RIVALDO, 1986)

Porém, dado o ambiente adverso, muitas dificuldades foram encontradas:

Com a nova Diretoria Executiva em 1986, e com a mudança da conjuntura políticoeconômica do País, o modelo circular de pesquisa foi enfraquecido. As reuniões de PNP foram esvaziadas, a falta de recursos prejudicou a gestão da pesquisa no formato preconizado, e a programação se fragmentou em projetos pontuais sem relação entre eles, com grande prejuízo para a produção da empresa. (PENTEADO et al., 2014, p. 45)

Conforme Penteado et al. (2014), foi nessa tentativa de revitalização da Embrapa e mudança da visão da sociedade sobre a mesma que foi elaborado o I Plano Diretor da Embrapa 
em 1987, com abrangência para o período de 1988 a 1992, porém, conforme os autores, o modelo circular permaneceu nesse período. Então, o I Plano Diretor foi uma tentativa de inserir uma visão de longo prazo no planejamento da Embrapa, mas que não rompia com as ferramentas de programação de pesquisa, a visão estratégica só foi inserida de fato no início da década seguinte.

Para Freitas Filho et al. (1999, p.43), a Embrapa adotou uma abordagem proativa a partir de 1989 , quando passou a utilizar "[...] a técnica de cenários alternativos para incorporar as incertezas e descontinuidades do ambiente externo a sua proposta institucional de futuro, ampliando a base de informações para tomada de decisões." O uso do planejamento estratégico foi incorporado por propiciar maior integração entre público interno e externo na definição da atuação futura, também foi congregado o conceito de qualidade total na rotina de gestão.

A partir do contexto institucional que passou a ser mais desafiador a organização incorporou as técnicas de planejamento estratégico e monitoramento do ambiente para definição de ações futuras como meio de promover uma mudança interna, tendo a capacidade de se adaptar às demandas da sociedade. E ao mesmo tempo interferiu na mudança institucional à medida que os conhecimentos e tecnologias difundidas modificaram a agricultura brasileira, também em sua estrutura e organização.

Porém, as mudanças começaram a ocorrer de fato a partir da gestão de Murilo Xavier Flores, que esteve à frente da presidência da Embrapa entre 1990 e 1995, um período de fortes pressões sobre a organização, dada a crise fiscal do Estado. Contudo, Cabral (2005) destaca que Flores teve maior autonomia para implementar as mudanças que julgava necessárias.

A partir daí, surgiu o Sistema Embrapa de Planejamento que emerge da "[...] avaliação geral, envolvendo funcionários e pessoas de fora da Embrapa. Partindo da ideia de que o PNP estava falido e de que era preciso adotar visão de sistemas produtivos, os projetos de pesquisa passaram a ser arcabouços maiores, onde se inseriam experimentos." (EMBRAPA, 2002, p. 81) Com isso se eliminava a ideia de pesquisador e projeto isolado e passava-se a trabalhar de forma integrada, o que acarretou em drástica diminuição do número de projetos, que foram agrupados. Segundo Embrapa (2002), passou-se de mais de 4 mil projetos para apenas 400.

Conforme Embrapa (2003), um passo importante para institucionalização do novo modelo de gestão na Embrapa aconteceu a partir da criação da Secretaria de Administração Estratégica, por meio da Deliberação de n⿳000/90 de 28 de junho de 1990, como uma estrutura ligada à presidência da empresa. Embrapa (1990) destaca que foram realizadas mudanças na 
estrutura organizacional da empresa para inserir a perspectiva de planejamento estratégico, que tinham também por objetivo adaptar-se às diretrizes do governo federal, de redução de gastos e maior agilidade administrativa, com oportunidade da Embrapa se envolver em programas nacionais de desenvolvimento agropecuário a serem propostos pelo governo federal. Então entre as providências tomadas a partir da Deliberação 008/90 está a extinção de diversas estruturas, a partir de 01 de julho de 1990, e criação de outras, entre elas a Secretaria de Administração Estratégica (SEA), que seria incumbida de: “[...] subsidiar o Presidente e a Diretoria Executiva na formulação, acompanhamento e avaliação das políticas e diretrizes globais da Empresa." (EMBRAPA, 1990, p.05)

Interessante observar que a Secretaria de Administração Estratégica foi um marco para a inserção dos conceitos relacionados à Estratégia e Planejamento Estratégico que começaram a ser pautados ainda na década de 1980, implementando um processo de mudança organizacional de modo a se adaptar às transformações que ocorriam no ambiente:

\footnotetext{
Esse processo de mudança que teve início no final da década de 80 , utilizando os instrumentos e métodos de planejamento e administração estratégica, contribuiu significativamente para que a Embrapa se consolidasse como uma instituição de referência em sua área de atuação no País e no exterior. Essa iniciativa evoluiu conduzindo a Embrapa aos seus Plano Diretor II e Plano Diretor III e, mais recentemente, na proposta do Plano Diretor IV. (EMBRAPA, 2004b, p. 11)
}

Segundo Freitas Filho et. al (1999), foram adotadas já no início da década de 1990 estratégias para integrar a nova prática de gestão, como a contratação de consultoria especializada da Faculdade de Administração e Economia da Universidade de São Paulo (FEA/USP), denominada "Programa de Estudos do Futuro". A partir desta, houve mobilização interna com capacitação dos recursos humanos para implementação do planejamento estratégico. Conforme Goedert et al. (1995), foi a partir de 1991 que o planejamento estratégico foi incorporado no cotidiano da empresa, cujo esforço aparece no II Plano Diretor da Embrapa, no Plano Diretor das Unidades Descentralizadas e no Plano Diretor da Sede. Mas apenas em setembro de 1992, com a Portaria no 324/92 que foi instituído o grupo de trabalho para "modernização institucional".

Para Goedert et al. (1995), em 1993 as mudanças de fato foram implementadas, com a criação do Sistema Embrapa de Planejamento (SEP), que passou a normatizar o planejamento para as unidades descentralizadas e indicar práticas para as demais organizações do Sistema Nacional de Pesquisa Agropecuária. O SEP era inovador, pois trazia conceitos de Gestão da 
Qualidade, com identificação dos clientes e das suas necessidades, e a partir destas orientava projetos, e se baseava em enfoque de $P \& D$, no qual a pesquisa e o desenvolvimento deveriam ser vistos como um processo contínuo e cíclico, aliados à abordagem sistêmica que propiciava visão abrangente do problema de pesquisa com uso de ferramentas em perspectiva interativa. (GOEDERT et al., 1995) Trata-se então de transformações institucionais que impuseram novas estruturas organizacionais no interior da Embrapa.

Então, foi a partir de 1993, com o II Plano Diretor da Embrapa que a visão de planejamento estratégico ganhou espaço em uma perspectiva de longo prazo, pautada na gestão da qualidade, em olhar além do produtor rural. Para Penteado et al. (2014) é com a revisão do modelo institucional da Embrapa, que ocorreu em 1992, que a noção de cadeia produtiva foi inserida em percepções regionais e de biomas, também a documentação das atividades passou ser mais enfatizada com o planejamento, prospecção de demandas e comunicação dos resultados. Ainda foi nesse período que foram criadas estruturas e ações que passam a coordenar a prospecção das necessidades e pressões impostas pelo ambiente, além da reação da organização a partir do seu planejamento, de modo a também integrar mais as ações das unidades.

Essas mudanças foram levadas adiante pelo sucessor de Murilo Flores, Alberto Duque Portugal, que já fazia parte da sua gestão como Diretor e, com isso, participou do processo de formulação do II PDE e das mudanças em curso, sua gestão ocorreu entre 1995 e 2002. Foi nesse período que houve a criação de toda uma estrutura interna, que permitiu que os objetivos alinhados no planejamento estratégico fossem de fato perseguidos nas atividades cotidianas e que isso pudesse ser acompanhado.

Foi criado um novo método de avaliação, com o Sistema de Avaliação e Premiação por Resultados (SAPRE), definido como "[...] conjunto de princípios, normas e procedimentos que orientam o estabelecimento de metas, a aferição dos resultados e a premiação de empregados, equipes e unidades da Embrapa." (EMBRAPA, 2002b, p. 97), sendo este implementado em 1996. O principal objetivo do SAPRE era identificar problemas e assuntos que deveriam ser priorizados na gestão da Embrapa. Outra estrutura criada nesse mesmo sentido foi o Sistema de Planejamento, Acompanhamento e Avaliação de Desempenho (SAAD), que estava vinculado à definição de metas e avaliação das atividades dos funcionários. E também, o Sistema de Avaliação de Unidade (SAU) para avaliação das unidades, conforme seus planos de trabalho. A partir destes, as unidades passaram a alinhar suas ações e objetivos aos Planos Diretores da Embrapa, e da avaliação destes planos e seus resultados passou a existir uma premiação para 
unidades e funcionários destacados, que começaram a ser reconhecidos com premiações incorporadas aos salários.

Foi criada toda uma estrutura interna, garantindo que as mudanças implementadas fossem de fato institucionalizadas e que as demandas de pesquisa prospectadas pelo planejamento fossem cumpridas. Pois passou a se vincular a avaliação funcional ao cumprimento de metas dos Planos Diretores das Unidades e estes ao Plano Diretor da Embrapa. Com isso, a organização percebeu tendências do ambiente, como a sinalização no início da década de 1990 para o aumento da importância de temas ligados à sustentabilidade, e ao mesmo tempo, retração de recursos por parte do setor público. A partir disso, a estrutura de gestão foi alterada a fim de garantir que novos objetivos de pesquisa vinculados a temas diferentes dos tradicionalmente tratados, passassem a também fazer parte da agenda de pesquisa. Desta forma, passou-se a projetar a mudança, e o ambiente no qual a Embrapa estava inserida começou a influenciar de maneira mais evidente em suas atividades de pesquisa, em um modelo mental que aos poucos foi se alterando em relação àquele que lhe deu origem.

Conforme Penteado et al. (2014), a partir da perspectiva da transformação do ambiente em que é operada a pesquisa agropecuária, com a evolução dos sistemas de comunicação e ampliação das redes de informática, que expandiram o acesso a informações, houve necessidade de incluir novas adaptações ao sistema de gestão. A partir disso, foi criado o Sistema Embrapa de Gestão que contempla o Modelo de Gestão Estratégica (MGE), implementado no ano de 2002, em substituição ao Sistema Embrapa de Planejamento, com enfoque de acompanhamento do ciclo da gestão dos projetos por completo, de modo a integrar melhor as atividades.

Ao analisar os documentos e informações disponíveis no site da Embrapa se percebe que a incorporação dos conceitos em torno da gestão e do planejamento estratégico foi difundida e institucionalizada em um amplo processo de convencimento interno, assim como a inclusão de temas considerados novos. Tanto que para o caso da MGE foi criada uma cartilha para instruir os funcionários sobre a importância da documentação e da mudança, do alinhamento organizacional de objetivos e da revisão das estratégias, vinculando metas institucionais a metas individuais e, assim, incluindo todos no processo de mudança, disponível no documento Embrapa (2000).

Conforme Penteado et al. (2014, p.51), o Sistema Embrapa de Gestão (SEG) criado em 2002 lançou uma nova agenda institucional, que "[...] organiza-se em macroprogramas (MPs) e contempla instrumentos para operacionalizar a indução de projetos e a formação de redes e 
arranjos cooperativos inovadores, para incrementar a priorização de atividades de pesquisa.". Foi a partir daí que as atividades da Embrapa se organizaram em quatro pilares: P\&D, Transferência de Tecnologia, Comunicação e Desenvolvimento Institucional, que seriam coordenados pelo Comitê Gestor da Programação, considerado um componente tático de gestão.

Conforme Embrapa (2008b), em meados dos anos 2000 a organização aprofundou seu processo de planejamento mais uma vez, para tanto, em 2006 criou o Comitê Gestor de Estratégias, para atuar na formulação da política de inovação da Embrapa e na análise e avaliação do desempenho da empresa. Em 2007 foi iniciado o processo de elaboração do V Plano Diretor, a partir do qual se alongou o prazo para a implementação das estratégias, que cobriu o período de 2008 a 2023. O documento Embrapa (2008b) ainda cita o Plano de Desligamento Incentivado (PDI) que foi implantado em 2005 com duração até 2009, como meio de renovação do quadro de funcionários a Embrapa, promovendo mudanças internas nas concepções de pesquisa.

No aprofundamento desse processo, a gestão de Pedro Arraes que presidiu a Embrapa entre 2009 e 2012, foi marcada pela reestruturação da inteligência estratégica da organização, com a criação do Sistema Agropensa. Houve também alteração da gestão da carteira de projetos, que passou a ser por portfólio, no qual eram agregados projetos afins em temas de importância estratégica, com maior articulação e coordenação entre as ações de Pesquisa e Desenvolvimento, Transferência de Tecnologia e Gestão e Comunicação. (EMBRAPA, 2019b)

Quem sucedeu Pedro Arraes foi Maurício Antônio Lopes, que presidiu a Embrapa de 2012 e 2018, e deu continuidade à estruturação do "Sistema Agropensa". Para Embrapa (2014), o seu grande desafio foi identificar as mudanças relevantes que ocorreram no ambiente e a partir disso fornecer informações para tomada de decisão, melhorando a capacidade de fornecer respostas às oportunidades e aos riscos que surgem no setor. Por isso, sua estrutura opera em rede a partir da lógica de cadeias produtivas, e tem como resultado o documento "Visão 2014-2034: o futuro do desenvolvimento tecnológico da agricultura brasileira" em Embrapa (2014).

Mais recentemente, em 2018, a Embrapa lançou o novo produto Agropensa, o documento "Visão 2030: o futuro da agricultura brasileira", o qual busca "[...] subsidiar a definição de novas ações estratégicas em CT\&I no desenvolvimento da agricultura e contribuir até 2030 para os Objetivos de Desenvolvimento Sustentável (ODS) propostos pelas Nações Unidas [...] (EMBRAPA, 2018, p.12) Demonstrando que a organização está atenta às tendências e discussões internacionais e que é capaz de fornecer subsídios à agricultura brasileira, no setor 
público e privado. Juntamente com esse documento, a Embrapa também organizou uma série com 18 e-books que atrelam os seus objetivos aos ODS, pois cada um dos títulos vincula a ação da Embrapa a cada um dos 17 ODS e ainda tem um livro intitulado "Pesquisa e Inovação Agropecuária na Agenda 2030: contribuições da Embrapa" com uma visão organizacional dos temas. Essa vinculação dos objetivos organizacionais à agenda internacional parece ter sido um dos grandes resultados da gestão de Lopes frente à Embrapa.

Maurício Lopes também mostrou à organização a importância dessa vinculação de agendas, tanto que em texto disponível no site da Embrapa (2019a), chama a atenção a importância da integração da Agenda 2030 nas perspectivas futuras da agricultura brasileira. Pois, este é um grande desafio que traz muitas oportunidades para o Brasil que foi o único país tropical a conseguir o status de potência agrícola, e a partir de uma agricultura fortemente baseada no conhecimento e na tecnologia tem contribuído para a sustentabilidade na medida que esse avanço de produção é feito com "poupança de recursos". Para tanto, Lopes (2019a) apresenta alguns temas e dimensões para as quais "as lideranças e tomadores de decisões, responsáveis por nortear e modelar o futuro da agricultura e da alimentação no País, em sintonia com a Agenda 2030" deverão estar atentos e fortemente ligados à sustentabilidade, Lopes mostra que atrelar o planejamento e as atividades da Embrapa à agenda internacional, vinculada aos ODS são uma grande oportunidade, e nisso pode ser destacada a pressão imposta pelo ambiente, que a partir de 2016 foi de redução drástica de recursos.

Em termos de conformação e gestão é interessante observar que atualmente o Agropensa é uma das principais estruturas para subsidiar a criação das estratégias de atuação da Embrapa. Esse sistema que está sob a coordenação da Secretaria de Inteligência e Relações Estratégicas (Sire). A qual tem como principal objetivo a elaboração de estudos prospectivos que contemplem e difundam conhecimentos para formulação de estratégias em Pesquisa, Desenvolvimento e Inovação (PD\&l), tanto para a Embrapa, como para outras organizações do setor agrícola. Em que o gerenciamento da mesma ocorre por meio de macroprogramas, portfólios e arranjos, onde os macroprogramas, que compreendem o conjunto de portfólios e arranjos. (EMBRAPA, 2019c)

As principais mudanças em torno da evolução do planejamento da Embrapa e sua estrutura foram trazidas nesta seção, e a partir disso parece importante destacar o papel de curto prazo que o planejamento tinha na Embrapa em suas duas primeiras décadas de atuação, sendo que principalmente nos anos 1970 a programação de pesquisa da empresa era um 
desdobramento dos planos do governo federal. Mas aos poucos o ambiente passou a se tornar mais adverso e impor pressões, por isso, a estrutura de monitoramento e formulação de objetivos e estratégias de atuação de longo prazo também foram organizadas, sobretudo a partir dos anos 1990, quando as questões de sustentabilidade parecem entrar na agenda da Embrapa com mais força. Mas, como se viu, esse é um processo dependente em sua trajetória. Então a partir do final da década de 1980 a Embrapa passou a divulgar seus planos de pesquisa, os Planos Diretores, principal documento de estratégia da organização.

\section{A Embrapa e a mudança de agenda}

As mudanças na estrutura de planejamento da Embrapa que evoluíram da programação de pesquisa agropecuária resultante do desdobramento dos planos nacionais para uma visão proativa e centrada no planejamento estratégico com monitoramento constante no ambiente, levaram também a uma mudança e diversificação da agenda de pesquisa. A organização passou a perceber as principais demandas que o ambiente lhe impunha e passou a internalizá-las.

Conforme verificado na seção anterior a visão de planejamento na Embrapa evolui ao longo do tempo para uma perspectiva estratégica, a qual passou a ser inserida a partir da década de 1990, período em que importantes transformações do ambiente impuseram novos desafios à organização. Entre eles cita-se a mudança política a partir da redemocratização, e que teve uma das consequências o avanço dos movimentos sociais na luta pela terra e integração de grupos até então excluídos das políticas agrícolas, o avanço das discussões em torno das questões ambientais e da perspectiva de desenvolvimento sustentável a partir de 1992 após a Conferência da ONU no Rio de Janeiro, e a crise econômica com redução dos gastos públicos e avanço do ideário neoliberal no Brasil a partir do final da década de 1980, mas avançando com privatizações especialmente a partir da década de 1990.

Em meio a tais transformações a Embrapa lançou em 1988 seu primeiro Plano Diretor na intenção de estruturar as ações a serem desenvolvidas nos próximos quatro anos, mas na análise do documento percebe-se que o mesmo se trata de uma programação de pesquisa. Mas, foi somente a partir de 1993 com a criação do Sistema Embrapa de Planejamento (SEP) que se passou a analisar de fato o ambiente no qual a organização estava inserida e cujo resultado em termos estratégicos pode ser visualizado a partir do II Plano Diretor da Embrapa. 
Por isso, na Figura 1 se faz uma análise dos objetivos estratégicos e prioridades delineadas em cada um dos Planos Diretores. Como se pode perceber pela Figura 1, se avança ao longo dos planos em um realinhamento para atender demandas que se formam no ambiente. Desse modo as questões ligadas à sustentabilidade ganham cada de mais espaço, e a preocupação com a produtividade, apesar de ainda se manter presente, não é mais vista como única prioridade.

Parte-se do I Plano Diretor que foi formulado em 1987, mas que vislumbrava a programação da pesquisa para o período de 1988 a 1992, no qual o objetivo central era de aumentar a produtividade da agricultura brasileira. O documento, Embrapa (1988) apresenta metas específicas para produtos e regiões consideradas prioritárias e envolvem tecnologias que tem a capacidade de reduzir a necessidade de recursos considerados escassos, bem como aumentar a produção por unidade de recursos utilizados, especialmente terra.

A partir do II Plano Diretor, a estrutura de planejamento estratégico já estava constituída e seus resultados parecem visíveis em uma diversificação de temas abordados, para além da produtividade e por inseriu objetivos estratégicos para a produção da Embrapa, calcado na busca pela eficiência, qualidade e equidade. Ou seja, questões qualitativas e ligadas à preocupação ambiental e social começam a aparecer. Por sua vez no III PDE, questões ambientais parecem tomar mais espaço dentro dos objetivos estratégicos, ao mesmo tempo que a questão da produtividade parece ser novamente reforçada à medida que emerge a chamada "Economia do Agronegócio". Algo que é reforçado no IV PDE, quando a preocupação com segurança alimentar e nutricional ganha mais espaço, em detrimento do mero abastecimento vinculado à produtividade que era destacada no I PDE. Além disso, tecnologias inovadoras ligadas à biotecnologia são destacadas. 


\section{PDE (1988-1992)}

- Aumento da produção de alimentos principalmente para atender população de baixa renda;

- Aumento da produtividade dos fatores de produção, principalmente nas regiões de ocupação antiga;

- Desenvolvimento de tecnoloigas para ampliação da fronteira agrícola, principalmente na Amazônia e Centro Oeste;

- Desenvolvimento de insumos mais eficientes para a agricultura;

- Preservação dos recursos naturais e sua racional utilização;

- Redução da dependência externa, especialmente em tecnologia de ponta.

II PDE (1994-1998)

- Incrementar a produção e a eficiência;

- Contribuir para resolver os problemas sociais e ambientais;

- Adequar a qualidade e as características de produtos, às demandas dos consumidores e intermediários finais;

- Gerar tecnologia para produtos e processos industriais;

- Adaptar tecnologias produzidas em outros países;

- Promover e agilizar a transferência e marketing de informações científicas e tecnológicas;

- Gerar tecnologias para produtos básicos de alimentação;

- Promover um salto qualitativo na pesquisa.

\section{PDE (1999-2003)}

- Soluções tecnológicas para a competitividade do agronegócio;

- Soluções tecnológicas para promover a sustentabilidade das atividades econômicas com equilíbrio ambiental;

- Soluções tecnológicas para diminuir desequilíbrios sociais;

- Soluções tecnológicas que forneçam matérias primas e alimentos que promovam a saúde e melhoria do nível nutricional e de qualidade de vida da população.

\section{PDE (2004-2007)}

- Inovação e arranjos institucionais para desenvolvimento da competitividade e da sustentabilidade do agronegócio;

- Desenvolvimento da capacidade produtiva dos pequenos produtores com sustentabiliade e competitividade;

- Segurança alimentar e nutricional;

- Uso sustentável de biomas;

- Biotecnologia avançada, inteligência artificial e sistemas de informação, ciclo hidrológico e balanço energético;

- Avanço da competitividade do agronegócio brasileiro.

V PDE (2008-2011-2023)

- Competitividade e a sustentabilidade da agricultura brasileira;

- Atingir novo patamar tecnológico competitivo em agroenergia e combustíveis;

- Intensificar o desenvolvimento de tecnologias para o uso sustentável dos biomas e a integração produtiva das regiões brasileiras;

- Prospectar a biodiversidade para o desenvolvimento de produtos diferenciados e com alto valor agregado em novos segmentos de mercado;

- Avanço da fronteira do conhecimento e incorporar novas tecnologias.

\section{PDE (2014-2034)}

- Manejo e aproveitamento sustentável dos biomas brasileiros;

- Resiliência dos ecossistemas nativos, tecnologias emergentes para sistemas agroalimentares e agroindustriais;

- Tecnologias de informação e comunicação e precisão para agricultura;

- Segurança biológica e zoofitossanitária;

- Aumentar produtividade com sustentabilidade;

- Pesquisa agropecuária para integração entre alimento-saúde-nutrição;

- Bioindustrias com foco em energia renovável;

- Química verde e novos materiais;

- Políticas públicas alinhadas ao mercado e desenvolvimento rural, inclusão produtiva da agricultura familiar, inovações gerenciais;

- Estratégias de informação para valorização da pesquisa agropecuária.

Fonte: Elaborado pelos autores, a partir de dados da pesquisa (2020) 
Analisando-se a figura 1, ainda se percebe que o V PDE avança para uma visão de uso estratégico da biodiversidade, ou seja, alia-se a ideia de eficiência econômica e produtividade com conservação ambiental, mantendo assim o foco inicial da produtividade e integrando a preocupação com a sustentabilidade em uma ótica vinculada ao capitalismo. O que também aparece bem claro no VI PDE no qual um dos objetivos estratégicos é "aumentar produtividade com sustentabilidade. Essas diferenças e percepções a partir da leitura dos Planos Diretores formulados pela Embrapa foram resumidos e podem ser analisados no Quadro 1.

Quadro 1 - Foco dos Planos Diretores da Embrapa

\begin{tabular}{|l|l|}
\hline I & $\begin{array}{l}\text { Pesquisa agropecuária, conhecimento técnico para aumento de produtividade } \\
\text { com propósito de abastecimento }\end{array}$ \\
\hline II & $\begin{array}{l}\text { Maior foco na demanda como elemento definidor das prioridades de pesquisa, } \\
\text { aumento da produtividade aliado à preocupação com questões ambientais e } \\
\text { sociais. Maior foco no planejamento e uso eficiente dos recursos públicos. }\end{array}$ \\
\hline III & $\begin{array}{l}\text { Mudança organizacional para realinhar o planejamento e a atuação da } \\
\text { Embrapa, conforme as mudanças no ambiente externo. Foco na } \\
\text { competitividade internacional, sustentabilidade, redução de desequilíbrios } \\
\text { sociais e segurança alimentar e nutricional. }\end{array}$ \\
\hline IV & $\begin{array}{l}\text { Competitividade do agronegócio brasileiro, mas com sustentabilidade } \\
\text { ambiental e inserção de agricultores familiares. Inovação como meio para } \\
\text { alcançar o desenvolvimento econômico e social, importância da conservação e } \\
\text { uso sustentável dos biomas. }\end{array}$ \\
\hline V & $\begin{array}{l}\text { - Aproveitar as oportunidades em nível mundial, que colocam o Brasil como } \\
\text { potência da agricultura e da agroenergia. Alinhar os objetivos de médio prazo } \\
\text { (2008 a 2011) aos objetivos do governo federal. }\end{array}$ \\
\hline VI & $\begin{array}{l}\text { Integração maior entre unidades da Embrapa e com outras organizações de } \\
\text { pesquisa. Inserção de nova metodologia de planejamento a partir do } \\
\text { Agropensa em 2015, com revisão permanente dos cenários utilizados, por meio } \\
\text { de diagnósticos, aferição e atualização desses. }\end{array}$ \\
\hline
\end{tabular}

Fonte: Elaborado pelos autores, com base em dados da pesquisa (2020).

No I Plano Diretor da Embrapa, o foco estava na questão do abastecimento que parece ser uma consequência do momento que o país vivia, de inflação alta e temores de desabastecimento, então era preciso aumentar a produção para baratear os custos com alimentação da crescente população urbana. Aliado a isso, há a preocupação com legitimar o trabalho da Embrapa e seus resultados em termos de tecnologias que garantam tal aumento de produtividade da agricultura brasileira.

No II Plano Diretor da Embrapa a importância de legitimar o trabalho e o uso dos recursos empregados no desenvolvimento da pesquisa é mais ressaltada e, a partir daí, a orientação para a demanda parece mais evidente. Ou seja, produzir tecnologias que agricultores e indústrias 
estejam necessitando. $\mathrm{E}$ isso também aparece relacionado a esse ambiente externo, em meados da década de 1990, momento de ajuste fiscal e abertura econômica, coincidindo com os primeiros anos do Plano Real, em que muitas empresas públicas foram privatizadas ou tiveram suas atividades encerradas. Por isso, a Embrapa enquanto organização pública, também precisava dar respostas ao recurso público investido na sua estrutura.

O I e II Planos Diretores, que abrangem o período de 1988 até 1998, parecem pertencer a um mesmo ciclo, de foco de pesquisa e planejamento em aumento de produtividade, respostas à sociedade e ainda muito envolvidas no ambiente de pesquisa da Revolução Verde. A preocupação com sustentabilidade aparece, mas de forma muito segmentada e principalmente no II PDE, a produtividade, o abastecimento e a eficiência no uso dos recursos públicos têm posição central.

No III Plano Diretor, a questão da competitividade internacional começa a constar de modo mais evidente, momento em que a agricultura brasileira passou a ser destacada internacionalmente como capaz de abastecer a crescente população mundial. O crescimento da China passou a influenciar e o Brasil avançou no processo de abertura econômica, momento em que a globalização tornou-se tendência internacional e avançaram tratativas de acordos internacionais como o Mercosul. O período do III Plano Diretor é 1999 a 2003, e 2002 por exemplo é o ano em que o Euro começou a circular como moeda única da União Europeia, com isso o bloco europeu completou todas as fases para uma integração econômica e monetária e se tornou referência e modelo para outros blocos. Assim, a discussão internacional em torno da ampliação do comércio internacional se alargava muito no período e, certamente, influenciou a tomada de decisões dos gestores públicos brasileiros em torno das possibilidades de incremento do comércio de produtos agrícolas.

O foco da pesquisa continuava sendo o aumento de produtividade, mas não mais apenas para o abastecimento interno como estava enfatizado no I PDE de forma muito forte, mas para aumentar exportações agrícolas e alcançar o destaque internacional nesse mercado. O III PDE também merece destaque, pois foi nele que se inaugurou o uso da visão como elemento norteador das atividades e planejamento da organização.

Mas, foi somente a partir do IV PDE que a preocupação com os desequilíbrios regionais, segurança alimentar e nutricional, questões social e ambiental começaram a se fazer mais presentes. Também em consonância com os objetivos impostos pela mudança política ocorrida nesse Brasil no período. 
Então aqui se sugerem 3 ciclos da pesquisa agropecuária, o primeiro entre 1988 e 1998, descritos no I e II Planos Diretores da Embrapa, cujo foco era o abastecimento interno via aumento de produtividade e eficiência no uso dos recursos públicos. O segundo ciclo presente no III Plano Diretor, entre 1999 e 2003, com foco na competitividade internacional do agronegócio brasileiro e uso eficiente dos recursos públicos empregados na pesquisa agropecuária pública. E, a partir de 2004, quando o foco na pesquisa passou a se centrar também na questão da qualidade do alimento e saúde humana decorrente da alimentação, sustentabilidade e desenvolvimento socioeconômico das diferentes regiões.

Mas, apesar dessas mudanças e inserção de novos temas, percebe-se que a preocupação com produtividade agropecuária é uma constante presente nos planos. Então, o que se pode perceber com a análise dos Planos Diretores da Embrapa é que a organização projeta uma mudança interna, e conforme as contribuições do referencial teórico dadas especialmente por Douglass North, essa mudança é incremental. Ela acontece aos poucos, e conforme North (2018) destaca, ela é carregada de path dependence, ou seja, novos temas ligados especialmente à sustentabilidade e aspectos qualitativos são incorporados, ao mesmo tempo se mantém atenção na produtividade, que já não é mais o foco central, mas se mantém nos objetivos organizacionais. Ao mesmo tempo, conforme contribuições de Veblen $(1898,1987)$, essa mudança surge de pressões do ambiente externo e das reações da organização, que o faz para sobreviver.

\section{Considerações finais}

A Embrapa foi criada no início da década de 1970 com o objetivo de modernizar a agricultura brasileira, para gerar conhecimentos acerca das condições e especificidades da agricultura brasileira e a partir disso criar tecnologias que incrementassem a produtividade. Dado

o cenário institucional da época o planejamento organizacional estava concentrado em reproduzir as demandas do governo, por isso os objetivos de pesquisa vinham como desdobramentos dos Planos Nacionais do governo federal.

Porém, à medida que o cenário político, econômico e social se modificou, novas demandas e pressões da sociedade surgiram. Com isso, para sobreviver a organização viu-se praticamente obrigada a conhecer e sistematizar tais demandas, para a partir delas delinear novos objetivos de pesquisa e também integrar os diferentes segmentos da sociedade às rodadas de programação de pesquisa. É nesse contexto que inicialmente, no final da década de 1970 
surgem os PNPs e o modelo circular de pesquisa e na década seguinte é formulado o I Plano Diretor da Embrapa. Porém, nesse período ainda não se conseguia vislumbrar objetivos comuns de longo prazo a toda estrutura organizacional que está distribuída em todo território nacional.

A partir, da década de 1990 a administração estratégica e as ferramentas do planejamento estratégico foram integrados à estrutura organizacional, passou-se então a analisar sistematicamente o ambiente externo e extrair as principais demandas da sociedade e tendências de mercados que passam a ser absorvidas organizacionalmente a partir de objetivos estratégicos. Nisso, as questões ligadas unicamente à produtividade deram espaço a temas emergentes e que privilegiam aspectos ligados à sustentabilidade, à segurança alimentar e nutricional em questões qualitativas com preocupações sociais e ambientais ao lado das econômicas e produtivistas.

Ao longo do tempo as estruturas de planejamento se tornaram mais robustas e utilizadas ferramentas de avaliação de resultados integradas à avaliação funcional e de unidades que fez com que efetivamente os objetivos estabelecidos fossem cumpridos. Observa-se no planejamento uma mudança organizacional, incorporando novos objetivos a partir de pressões do ambiente, porém, há path dependence à medida que as preocupações com a produtividade mantêm-se presentes.

\section{Referências}

CABRAL, J. Irineu. Sol da manhã: memória da Embrapa. Brasília: UNESCO, 2005.

CASTRO, Ana Célia. Ciência e Tecnologia para Agricultura: uma análise dos planos de desenvolvimento. Cadernos Difusão de Tecnologia. Vol. 1. nำ3. 1984.

CHIAVENATO, Idalberto. Introdução à Teoria Geral da Administração: uma visão abrangente da moderna administração das organizações. 7. ed. Rio de Janeiro: Elsevier, 2003.

DUARTE, Jorge. Prosa com Eliseu: entrevista a Jorge Duarte. Brasília: Embrapa, 2018.

EMPRESA BRASILEIRA DE PESQUISA AGROPECUÁRIA - EMBRAPA. Boletim de Comunicações Administrativas, Brasília, ano 1, n. 1, 1974.

EMPRESA BRASILEIRA DE PESQUISA AGROPECUÁRIA - EMBRAPA. I Plano Diretor da Embrapa: 1988-1992. Brasília: Secretaria de Planejamento, 1988.

EMPRESA BRASILEIRA DE PESQUISA AGROPECUÁRIA - EMBRAPA. Boletim de Comunicações Administrativas. Ano XVI. №25. Brasília: Embrapa, 1990.

EMPRESA BRASILEIRA DE PESQUISA AGROPECUÁRIA - EMBRAPA. II Plano Diretor da Embrapa: 1994-1998. Brasília: Embrapa-SPI, 1994. 
EMPRESA BRASILEIRA DE PESQUISA AGROPECUÁRIA - EMBRAPA. III Plano Diretor da Embrapa: 1999-2003. Brasília: Embrapa-SPI, 1998.

EMPRESA BRASILEIRA DE PESQUISA AGROPECUÁRIA - EMBRAPA. Pesquisa Agropecuária e Qualidade de Vida: a história da Embrapa. Brasília: Embrapa, 2002.

EMPRESA BRASILEIRA DE PESQUISA AGROPECUÁRIA - EMBRAPA. Relatório de gestão 2002. Brasília, DF: Embrapa, 2003.

EMPRESA BRASILEIRA DE PESQUISA AGROPECUÁRIA - EMBRAPA. IV Plano Diretor da Embrapa: 2004-2007. Brasília: Embrapa, 2004a.

EMPRESA BRASILEIRA DE PESQUISA AGROPECUÁRIA - EMBRAPA. Relatório de Gestão da Embrapa 2003. Brasília: Embrapa, 2004b.

EMPRESA BRASILEIRA DE PESQUISA AGROPECUÁRIA - EMBRAPA. V Plano Diretor da Embrapa: 2008-2011-2023. Brasília: Embrapa, 2008a.

EMPRESA BRASILEIRA DE PESQUISA AGROPECUÁRIA - EMBRAPA. Balanço Social 2007. Brasília: Embrapa, 2008b.

EMPRESA BRASILEIRA DE PESQUISA AGROPECUÁRIA - EMBRAPA. Visão 2014-2034: o futuro do desenvolvimento tecnológico da agricultura brasileira. Brasília, DF: Embrapa, 2014.

EMPRESA BRASILEIRA DE PESQUISA AGROPECUÁRIA - EMBRAPA. VI Plano Diretor da Embrapa: 2014-2034. Brasília: Embrapa, 2015.

EMPRESA BRASILEIRA DE PESQUISA AGROPECUÁRIA - EMBRAPA. Visão 2030: o futuro da agricultura brasileira. - Brasília: Embrapa, 2018.

EMPRESA BRASILEIRA DE PESQUISA AGROPECUÁRIA - EMBRAPA. Embrapa lança plataforma de inteligência estratégica. Disponível em: https://www.embrapa.br/busca-de-noticias//noticia/1490628/embrapa-lanca-plataforma-de-inteligencia-estrategica Acesso em 28 de setembro de 2019a.

EMPRESA BRASILEIRA DE PESQUISA AGROPECUÁRIA - EMBRAPA. Pedro Arraes é reconduzido à Presidência da Embrapa. Disponível em: https://www.embrapa.br/busca-de-noticias//noticia/1481723/pedro-arraes-e-reconduzido-a-presidencia-da-embrapa Acesso em 01 de setembro de $2019 b$.

EMPRESA BRASILEIRA DE PESQUISA AGROPECUÁRIA - EMBRAPA. O que é o Agropensa? Disponível em: https://www.embrapa.br/agropensa/sistema-agropensa Acesso em 28 de setembro de 2019c.

FONSECA, Pedro C. D. Sobre a Intencionalidade da Política Industrializante no Brasil na Década de 1930. Revista de Economia Política, São Paulo, v.23, no 1, jan/mar 2003.

FREITAS FILHO, Antônio de. Planejamento Estratégico: conceitos e metodologia para sua formulação. Brasília: Embrapa- DPL, 1989.

GONÇALVES NETO, Wenceslau. Estado e agricultura no Brasil: política agrícola e modernização econômica brasileira 1960-1980. São Paulo: HUCITEC, 1997.

GOEDERT, W. J.; CASTRO, A. M.G.; PAEZ, M.L.D’A. O Sistema Embrapa de Planejamento. Revista de Administração, São Paulo, v.30 no4, out/dez, 1995.

LOPES, Maurício Antônio. A Agricultura Brasileira na Agenda Global de Desenvolvimento Sustentável. Embrapa, Brasília-DF, s.d. Disponível em: https://www.embrapa.br/olhares-para- 
2030/artigo/-/asset_publisher/SNN1QE9zUPS2/content/mauricio-antonio-

lopes?inheritRedirect=true Acesso em: 03 set. 2019b.

MANTZAVINOS, C.; NORTH, Douglass; SHARIQ, Syed. Learning, Institutions, and Economic Performance. Perspectives on Politics, Cambridge, v.2, nำ1, 2004.

NORTH, Douglass. Institutions. The Journal of Economic Perspectives, v. 5, no 1, 1991.

NORTH, Douglass. Economic Performance Through Time. The American Economic Review, v. 84, no 3, 1994.

NORTH, Douglass. Understanding the Process of Economic Change. Princeton, New Jersey: Princeton University Press, 2005.

NORTH, Douglass. Instituições, Mudança Institucional e Desempenho Econômico. Trad. MORALES, Alexandre. São Paulo: Três Estrelas, 2018.

PENTEADO, Maria I. de O.; FONTES, Ruy R.; CAMPOS, Fernando A.de A.; EUCLIDES FILHO, Kepler. A Trajetória do Planejamento na Embrapa. Cadernos de Ciência \& Tecnologia, Brasília-DF, v. 31, nำ1, 2014.

RIVALDO, Ormuz Freitas. Estratégias para o fortalecimento do Sistema Brasileiro de Pesquisa Agropecuário. Brasília: Embrapa, 1986.

SAMUELS, Warren J. The Present State of Institutional Economics. Cambridge Journal of Economics, v.19, 1995.

VEBLEN, Thorstein. Why is Economics not an Evolutionary Science? Quarterly Journal of Economics, v.12, no 4, 1898.

VEBLEN, Thorstein. A Teoria da Classe Ociosa: um estudo econômico das instituições. Trad: Krähenbühl, Olívia. 2a ed. São Paulo: Nova Cultural, 1987. 